\title{
Optimization and Characterization of Essential Oil Nanoemulsions Using Ultrasound for New Ecofriendly Insecticides
}

\author{
Emiliano Jesser, Cristhian Yeguerman, Valeria Gili, Graciela Santillan, Ana Paula Murray, \\ Claudia Domini, and Jorge Omar Werdin-González*
}

Cite This: https://dx.doi.org/10.1021/acssuschemeng.0c02224

Read Online

\begin{abstract}
ACCESS
山ll Metrics \& More

ABSTRACT: This study developed and evaluated the toxicological effects of new stable nanoemulsions (NEs) of peppermint essential oils (EOs) and palmarosa EO + linalyl acetate (LA) using ultrasound cavitation. Moreover, the study analyzed the effect of LA in the stabilization process of palmarosa NEs. Peppermint NEs had sizes of $34 \mathrm{~nm}$ and polydispersity index (PDI) values of 0.424 , whereas palmarosa NEs showed sizes of $15 \mathrm{~nm}$ and a PDI of 0.078 . Peppermint NEs were stable for 30 days and palmarosa NEs for 120 days. The insecticidal effect of NEs was also evaluated against $C x p$. pipiens and Plodia interpunctella larvae. In Culex pipiens pipiens, the $\mathrm{LC}_{50}$ values were $31.24 \mathrm{ppm}$ for peppermint $\mathrm{NEs}$ and 32.30 ppm for palmarosa + LA NEs. In P. interpunctella, the NEs were combined with $\beta$ cypermethrin and the $\mathrm{LC}_{50}$ values were $0.12 \mu \mathrm{g}$ larvae ${ }^{-1}$ for peppermint NEs and $0.23 \mu \mathrm{g}_{\text {larvae }}{ }^{-1}$ palmarosa + LA NEs. In addition, the NEs showed no toxicity effect in nontarget organisms such as Artemia salina and Tenebrio molitor. Finally, viability on mammalian cell culture models was evaluated and it was also observed that NEs did not affect the cell viability after 3 and 7 days of exposure.
\end{abstract}

Article Recommendations

KEYWORDS: larvicidal bioassay, ecotoxicological bioassay, cell viability, ultrasound, EO nanoemulsion

\section{INTRODUCTION}

Climate change could result in expansion of vector ranges from endemic places to nonendemic areas. ${ }^{1}$ In addition, many studies have demonstrated that, generally because of the increase in temperature, field populations of mosquitoes are likely to accelerate their development. ${ }^{2}$ Mosquitoes can transmit many pathogens, which can produce important diseases, such as dengue, malaria, and filariasis. ${ }^{3}$ For instance, Culex pipiens pipiens Say (Diptera: Culicidae) (Cx. p. pipiens) has shown to play a critical role in the transmission of lymphatic filariasis caused by Wuchereria bancrofti and other important arboviruses. ${ }^{4}$

Climate change has already been affecting agriculture and food systems in different regions, especially in developing countries. ${ }^{5}$ Therefore, an important factor in increasing food supply is improving the postharvest and storage practices to reduce food loss, which are caused by insects. ${ }^{6}$ Plodia interpunctella, Hübner (Lepidoptera: Pyralidae), the Indian meal moth, is a cosmopolitan pest and it infests different stored cereal products, dried vegetables, fruits, and nuts. Losses caused by larvae include the direct consumption of kernels and indirect damage because of the presence of larval farces, silkweb, and body fragments.

Synthetic insecticides are the most important products in mosquito and Indian meal moth control practices. However, these products produce undesired environmental impacts and side effects on human health. ${ }^{8}$ Essential oils (EOs) are viewed as an ecofriendly alternative to the use of conventional insecticides to control pests. ${ }^{9}$ Different studies have demonstrated that EOs have toxic, fumigant, and repellent effects on $C x$. p. pipiens and P. interpunctella. ${ }^{10-13}$ Nevertheless, EOs have showed some disadvantages, such as instability, volatility, and low solubility in water, which may limit their applications. ${ }^{13}$

Nanotechnology facilitates the development of new nanoformulations based on EOs in aqueous solutions, making bioinsecticides more effective and more environmentally friendly. ${ }^{14}$ Over the last few years, one of the most promising innovations in the field of insect pest control has been the nanoemulsions (NEs) of different products. ${ }^{15}$ NEs are colloidal delivery systems, with high thermodynamic stability, solubility, and higher bioavailability. Besides, they have showed a particle size range from 1 to $100 \mathrm{~nm} .{ }^{16} \mathrm{NEs}$ can be produced using low-energy as well as high-energy methods. Furthermore,

Received: March 22, 2020

Revised: April 28, 2020

Published: May 11, 2020 
some high-energy methods, such as high pressure homogenizer, ultrasonicator, or high shear homogenizer, use lower concentrations of surfactant compared with the low energy methods. ${ }^{17}$ New investigations informed that NEs based on EOs can be formulated using a liquid whistle hydrodynamic cavitation reactor, a microfluidizer, or an ultrasonic probe. ${ }^{18-20}$ The ultrasonic technique uses an ultrasonic probe, which produces waves to reduce the droplets from the macroemulsion. $^{21}$ The ultrasonication waves provide the energy forces with a higher intensity to turn mechanically broken larger droplets into smaller ones. ${ }^{16}$ Ultrasonication offers some advantages, such as a better control over formulation variables and a low production cost. ${ }^{22}$

Simultaneously, with the development of nanoformulations in the insect pest management field, econanotoxicology emerges as a novel discipline focused on the potential hazards of these products when they reach the environment. Many aquatic animals such as crustacean, mollusks, and fish have been used as models to evaluate the toxicological effects of several nanomaterials. ${ }^{23-25}$ Terrestrial models have involved insects, earthworms, mammalian cell lines, and so forth. ${ }^{26-28}$

Our work focused on the physicochemical characterization of NEs obtained from peppermint and palmarosa + linalyl acetate (LA), the analysis of LA in the stabilization of palmarosa NEs, and the efficacy of NEs against larvae of $C x p$. pippiens and $P$. interpunctella. Moreover, we evaluated the potential influence of NEs on the nontarget aquatic model Artemia salina, L. (Anostraca: Artemiidae), and on the terrestrial model Tenebrio molitor L. (Coleoptera: Tenebrionidae). We also investigated the effect of NEs on the viability of a mammalian cell culture model.

The overall objective was to develop an efficient bioinsecticide nanoformulation that can be used for safer management of pest insects as well as an improvement in the knowledge of the econanotoxicological field.

\section{MATERIALS AND METHODS}

Materials. Tween 80, LA, and $\beta$-cypermethrin were purchased from Sigma-Aldrich Commercial. Analytical grade Acetone (Dorwill, Argentina) was used as the solvent. The peppermint and palmarosa EOs were procured from Swiss-Just (manufactured under supervision and control of Ulrich Justrich AG, Walzenhausen, Switzerland).

The gas chromatography-mass spectrometry analysis of EOs showed that palmarosa presented geraniol $(\mathrm{G})(77.07 \%)$ and LA $(9.13 \%)$ as a main compound, and peppermint had menthol (52.51\%), isomenthone (16.9\%), and $p$-menthan-3-ona (10.03\%) as major substances.

Alpha-MEM (1.36 mM Ca $\left.{ }^{2+} ; \mathrm{CaCl}_{2} \cdot 2 \mathrm{H}_{2} \mathrm{O} 0.2 \mathrm{~g} / \mathrm{L}\right)$ and Neutral Red dye were purchased from Sigma-Aldrich (St. Louis, MO, USA). Fetal bovine serum (FBS) was procured from Natocor (Córdoba, Argentina).

Target and Nontarget Organisms. Cx p. pipiens was identified at the Laboratorio de Zoologia Invertebrados II, Universidad Nacional del Sur (UNS) Argentina. The mosquito larvae were maintained in an acclimate room at $27 \pm 1{ }^{\circ} \mathrm{C}, 45-50 \%$ r.h., and 16:8 $\mathrm{h} \mathrm{L} / \mathrm{D}$.

$P$. interpunctella were fed with a mixture of maize flour, wheat flour, powdered milk, honey, and glycerin of analytical grade (2:1:1:1:1 w/ w). The colonies grew in plastic containers $(13 \mathrm{~cm}$ diameter $\times 30 \mathrm{~cm}$ high) at $27 \pm 1{ }^{\circ} \mathrm{C}, 45-50 \%$ r.h., and 16:8 h L/D.

In order to obtain $48 \mathrm{~h}$-old nauplii from A. salina, the cysts were put in distilled water for $24 \mathrm{~h}$ to hydrate them. After that, they were moved to artificial synthetic seawater $(33 \mathrm{ppm})$ at $27{ }^{\circ} \mathrm{C}$ with continuous illumination and aeration for $24 \mathrm{~h}$, where they start to hatch.
Colonies of T. molitor were kept in a growth chamber and stored in darkness. The colonies grew in plastic containers of $20 \mathrm{~cm} \times 20 \mathrm{~cm} \times$ $30 \mathrm{~cm}$ (length $\times$ width $\times$ height). Each one contained a mixture of wheat flour, maize flour, and oats $(2: 1: 1 \mathrm{w} / \mathrm{w})$.

NE Formulation and Characterization. The NEs were elaborated following Jesser et al. ${ }^{29}$ Briefly, peppermint EO or palmarosa EO + LA (in different ratios) were mixed with Tween 80 and $25 \mathrm{~mL}$ of double-distilled water. Then, the emulsion was stirred at $700 \mathrm{rpm}$ for $2 \mathrm{~min}$ and moved into a plastic container $(3 \mathrm{~cm}$ diameter $\times 50 \mathrm{~cm}$ high). Sonics Vibra cell, VCX 130 with a titanium probe tip $(9.5 \mathrm{~mm}$ diameter, $130 \mathrm{~W}$ nominal power, $20 \mathrm{kHz}$ frequency) were used to obtain NEs. Sonication parameters were $65 \mathrm{~W}$ and an effective sonication time of $120 \mathrm{~s}$ by cycles of $30 \mathrm{~s}$ on $/ 20 \mathrm{~s}$ off in order to obtain stable NEs.

The average droplet size and the polydispersity index (PDI) was determined using dynamic light scattering (DLS) equipment (Zetasizer nano ZEN 3690 model, Malvern, UK). All experiments were performed at room temperature three times.

The stability of the emulsion over time was also analyzed. Thus, the droplet size and the visual appearance were registered for 120 days. The samples were stored at $25^{\circ} \mathrm{C}$ and they were observed one time a week. Three replicates of each samples were carried out.

LA: Role in Palmarosa NE Formation. As palmarosa EO alone is unable to produce a stable nanosystem, a comparative study was performed using the oil or G mixed with LA in order to determine the possible phenomena involved in the stabilization process of NEs. In consequence, different ratios of palmarosa oil and LA (0.5:0.5, 0.6:0.4, $0.7: 0.3$, and $0.8: 0.2)$ were mixed. Then, Tween 80 was added to this mixture (2:1). After that, double-distilled water was incorporated and stirred at $700 \mathrm{rpm}$ for $2 \mathrm{~min}$ to attain a homogeneous emulsified phase. The same ratios and steps were followed for the elaboration of G + LA NEs. Moreover, for all the NEs, the ultrasound parameters were maintained at $65 \mathrm{~W}$, the cycles were $30 \mathrm{~s}$ on/20s off, and the sonication time was 2 min.

Toxicity Bioassays. Cx p. pipiens Bioassays. Twenty mosquito larvae (fourth instar) were used in the assay in conformity with the $\mathrm{WHO}^{30}$ and the experiments were achieved in quadruplicate $(n=80)$. For EO bioassays, EOs were added in tap water with Tween $80(1 \%$ $\mathrm{p} / \mathrm{v}$ ) and for the NEs, they were added in tap water alone. The concentration of EOs or their NEs ranged from 10 to $250 \mathrm{ppm}$. Untreated (tap water alone) and surfactant (Tween 80 in the corresponding ratio) controls were assayed. The bioassays were performed at $27 \pm 1{ }^{\circ} \mathrm{C}, 45-50 \%$ r.h., and $16: 8 \mathrm{~h} \mathrm{~L} / \mathrm{D}$.

$P$. interpunctella Bioassays. The determination of acute toxicity, measured as mortality after $72 \mathrm{~h}$ of exposure, was made through topical application of peppermint and palmarosa $\mathrm{EO}+\mathrm{LA}$ or their NEs and $\beta$-cypermethrin to the fourth instar of $P$. interpunctella larvae $(n=10)$. A pretreatment was carried out using a sublethal dose of the EO $\left(20 \mu \mathrm{g} \mathrm{larva}^{-1}\right)$ or the NEs at an equal dose. After $2 \mathrm{~h}$, insects were exposed to $\beta$-cypermethrin solution in doses from 0.005 to $5 \mu \mathrm{g}$ larva ${ }^{-1}$ (topically applied). As control, acetone or surfactant alone (in the corresponding ratio) was used. All experiments were performed in quadruplicate.

Ecotoxicological Bioassays. A. salina Bioassays. In the present work, 48 h-old nauplii were exposed to peppermint and palmarosa EO and their NEs for $24 \mathrm{~h}$. Briefly, 20 nauplii were transferred to each sample vial containing $4 \mathrm{~mL}$ of freshly prepared synthetic seawater alone. After that, EOs or their NEs were added. The products were tested at concentrations ranging from 25 to $100 \mathrm{ppm}$ in order to obtain $\mathrm{LC}_{50}$ values. Untreated and Tween 80 controls were assayed. Tests were performed in quadruplicate.

T. molitor Bioassays. To determine the combined effect of EOs or NEs and $\beta$-cypermethrin in T. molitor, the same process for the $P$. interpunctella bioassays was performed. A pretreatment was carried out using a sublethal dose of the EO $\left(20 \mu \mathrm{g} \mathrm{larva}^{-1}\right)$ or the NEs at an equal dose. After a $2 \mathrm{~h}$ pretreatment, acetonic solutions of $\beta$ cypermethrin were applied in doses ranging from 0.003 to $0.06 \mu \mathrm{g}$ larva $^{-1}$. Acetone or surfactant alone was used as control. All experiments were performed in quadruplicate. 
Table 1. Characterization of Peppermint EO Formulations Elaborated by Ultrasound Technique ${ }^{a, b}$

\begin{tabular}{|c|c|c|c|c|c|c|}
\hline oil/surfactant & diam. size $(n m) \pm S E^{c}$ & & $\mathrm{PDI} \pm \mathrm{SE}^{c}$ & & stability after $72 \mathrm{~h}$ & visual appearance \\
\hline $1: 1$ & $102.5 \pm 56.04$ & $\mathrm{a}$ & $0.296 \pm 0.015$ & a & no & whitish \\
\hline $1: 1.5$ & $65.11 \pm 48.15$ & $\mathrm{a}$ & $0.479 \pm 0.014$ & $\mathrm{~b}$ & no & translucent \\
\hline $1: 2$ & $33.97 \pm 33.16$ & $\mathrm{a}$ & $0.424 \pm 0.008$ & $b$ & $\mathrm{Si}$ & transparent \\
\hline
\end{tabular}

${ }^{a} N=3$ replicates. ${ }^{b}$ For each column, different letters indicate significant statistical differences $(P<0.05) .{ }^{c} \mathrm{SE}=$ standard error $(\sigma / \sqrt{ } n)$.

Table 2. Characterization of Palmarosa + LA EO Formulations Elaborated by Ultrasonic Technique ${ }^{a, b}$

\begin{tabular}{|c|c|c|c|c|c|c|c|}
\hline oil/LA/Tween 80 & LA (\%) & Diam. size $(\mathrm{nm}) \pm \mathrm{SE}^{c}$ & & $\mathrm{PDI} \pm S E^{c}$ & & stability after $72 \mathrm{~h}$ & visual appearance \\
\hline $0.5: 0.5: 2$ & 50 & $14.77 \pm 1.63$ & $\mathrm{a}$ & $0.078 \pm 0.020$ & $\mathrm{a}$ & yes & transparent \\
\hline $0.6: 0.4: 2$ & 40 & $44.73 \pm 34.25$ & $\mathrm{~b}$ & $1 \pm 0.0$ & $\mathrm{~b}$ & yes & translucent \\
\hline $0.7: 0.3: 2$ & 30 & $61.79 \pm 55.28$ & $\mathrm{~b}$ & $1 \pm 0.0$ & $\mathrm{~b}$ & yes & translucent \\
\hline $0.8: 0.2: 2$ & 20 & $223.3 \pm 50.59$ & c & $0.193 \pm 0.017$ & c & no & white \\
\hline $1: 2$ & 0 & $300.2 \pm 53.24$ & $\mathrm{c}$ & $0.148 \pm 0.021$ & $\mathrm{~d}$ & no & white \\
\hline
\end{tabular}

${ }^{a} N=3$ replicates. ${ }^{b}$ For each column, different letters indicate significant statistical differences $(P<0.05) .{ }^{c} \mathrm{SE}=$ standard error $(\sigma / \sqrt{ } n)$.

Viability on Mammalian Cell Culture Models. An osteoblast cell culture was obtained from calvaria of 3-5-day-old neonatal rats from the Laboratorio de Quimica Biológica A, UNS, Argentina, according to Katz et al. ${ }^{31}$ All procedures were carried out in conformity with the Guide for the Care and Use of Laboratory Animals published by the US National Institutes of Health (NIH Publication no. 85-23, revised 1996) under protocol no. 012/2014 of Institutional Animal Care and Use Committee (CICUAE), UNS, Argentina.

Cells were seeded at a density of 10,000 cells $\mathrm{cm}^{-2}$ in plates of 48 multiwell and cultured for 3-4 days in $\alpha$-MEM supplemented with $10 \% \mathrm{FBS}$, in a humidified atmosphere $\left(5.5 \% \mathrm{CO}_{2}\right)$ at $37{ }^{\circ} \mathrm{C}$. When cells reached $80 \%$ confluence, they were starved in $1 \%$ FBS medium for $7-16 \mathrm{~h}$ before starting treatment. They were performed by replacing the starved medium with a treated medium which contained the NEs at $C_{90}$ values reached in $C x p$. pipiens larvae bioassays (peppermint NEs $=46.73$ ppm; palmarosa + LA NEs $=47.25 \mathrm{ppm})$. Two control conditions were also assayed: one containing the medium alone and the other containing the medium + Tween 80 (in the corresponding ratio). Control or treatment mediums were renewed every 2-3 days. The cell viability was recorded after $24 \mathrm{~h}$, $72 \mathrm{~h}$, and 1 week exposure and cell images were captured using a 13 Mpx camera in order to illustrate the different treatments. For each experiment, eight samples were assayed.

The determination of cell viability was carried out using Neutral Red staining. After the treatments, cells were washed with PBS $1 \times$ and stained with Neutral Red for $3 \mathrm{~h}$, at $37{ }^{\circ} \mathrm{C}$. The dye excess was removed with PBS $1 \times$, and photographs of the cells were taken. Finally, the dye incorporated into the cells was extracted with a remover solution (50\% ethanol $96 \%$, 49\% deionized water, $1 \%$ glacial acetic acid), and quantified at $540 \mathrm{~nm}$ in a spectrophotometer with a plate reader.

Statistical Analysis. Values of means of diameter size, PDI, and cell viability parameter were subjected to ANOVA analysis and compared using the post hoc test of multiple comparisons by Bonferroni (InfoStat software). Means, SE $(\sigma / \sqrt{ } n)$, and statistical results are informed in Tables $1-4$ and Figure 7.

For Cx p. pipiens and A. salina, the mortality was recorded after a 24 $\mathrm{h}$ exposure, and for Plodia interpuctella and T. molitor, after $72 \mathrm{~h}$ in order to calculate $\mathrm{LC}_{50} / \mathrm{LC}_{90}$ or $\mathrm{LD}_{50} / \mathrm{LD}_{90}$ values, respectively. Statistics were carried out using SPSS 25.0. The values were considered significantly different if their $95 \%$ confidence intervals did not overlap.

\section{RESULTS AND DISCUSSION}

NE Study. Based on Jesser et al., ${ }^{29}$ and in order to determine the minimum possible droplet size of peppermint and palmarosa + LA NEs, the ultrasonic parameters used in this work were: ultrasound power $=65 \mathrm{~W}$, sonication time $=2$
Table 3. Average Diameter and PDI for Peppermint and Palmarosa + LA NEs for 120 days of Storage at $25^{\circ} \mathrm{C}^{a, b, c}$

$\begin{array}{lrcccc}\text { nanoemulsiones } & \text { days } & \text { size }(\mathrm{nm}) \pm \mathrm{SE} & & \text { PDI } \pm \text { SE } & \\ \text { palmarosa + LA } & 1 & 14.73 \pm 1.63 & \text { a } & 0.078 \pm 0.020 & \text { a } \\ & 30 & 14.77 \pm 4.67 & \text { a } & 0.124 \pm 0.016 & \text { b } \\ & 60 & 15.00 \pm 5.78 & \text { a } & 0.176 \pm 0.019 & \text { b } \\ \text { peppermint } & 120 & 18.01 \pm 3.65 & \text { a } & 0.097 \pm 0.013 & \text { a } \\ & 1 & 33.97 \pm 33.16 & \text { a } & 0.424 \pm 0.008 & \text { a } \\ & 30 & 70.10 \pm 33.95 & \text { a } & 0.624 \pm 0.016 & \text { b }\end{array}$

${ }^{a} . N=3$ replicates. ${ }^{b} \mathrm{SE}=$ standard error $(\sigma / \sqrt{ } n) .{ }^{c}$ For each column, different letters indicate significant statistical differences $(P<0.05)$.

min, cycles $=30 \mathrm{on} / 20 \mathrm{off}$, and ultrasonic probe distance (the distance between the bottom of the container and the ultrasonic probe) $=3.7 \mathrm{~cm}$ (Figure 1). The authors demonstrated that applying more power beyond these values becomes unnecessary and unproductive, as it consumes extra energy, and can result in the "overprocessing" phenomenon.

The autocorrelation function (Figures 2-4, column 3) shows that the NE parameters were correctly estimated. Table 1 shows the different ratios of the surfactant/peppermint EO. Generally, when the surfactant concentration was increased, the droplet size from peppermint NEs was reduced and the macroscopic aspect of the NEs appears to be transparent. Even though based on PDI values, all system tend to be polydisperse. The whitish emulsions were formed when the peppermint $\mathrm{EO} /$ Tween 80 ratio was $1: 1$ with an average size of $102.5 \pm 56.04 \mathrm{~nm}$ and the PDI value being $0.296 \pm 0.015$. The NEs with 1:1.5 ratios of peppermint EO/Tween 80 had a droplet diameter of $65.11 \pm 48.15 \mathrm{~nm}$ and the PDI value of $0.479 \pm 0.014$, and the macroscopic aspect was translucent. In the end, transparent NEs were achieved using a 1:2 peppermint EO/Tween 80 ratio. These NEs showed sizes of $33.97 \pm 33.16 \mathrm{~nm}$ and the PDI value of $0.424 \pm 0.008$, and were stable after 30 days (Figure 2). However, no significant differences were found between the NE droplet sizes $(P>$ $0.05)$.

It is important to point out that the palmarosa $\mathrm{EO}$ alone at the highest Tween 80 ratio (1:2) was unable to produce a stable NE (droplet diameter $=300.2 \pm 53.24 \mathrm{~nm}$, PDI $=0.148$ \pm 0.021 macroscopic aspect $=$ white emulsion). The addition of LA to the coarse emulsion made the NE production possible. The characterization of the droplet size and the PDI 
Table 4. Characterization of G + LA Formulations Elaborated by Ultrasonic Technique ${ }^{a, b}$

\begin{tabular}{|c|c|c|c|c|c|c|c|}
\hline G/LA/surfactant & LA (\%) & Diam. size $(\mathrm{nm}) \pm \mathrm{SE}^{c}$ & & $\mathrm{PDI} \pm \mathrm{SE}^{c}$ & & stability after $72 \mathrm{~h}$ & visual appearance \\
\hline $0.5: 0.5: 2$ & 50 & $13.95 \pm 1.515$ & $\mathrm{a}$ & $0.097 \pm 0.019$ & $\mathrm{a}$ & yes & transparent \\
\hline $0.6: 0.4: 2$ & 40 & $15.00 \pm 3.084$ & $\mathrm{a}$ & $0.176 \pm 0.017$ & $\mathrm{~b}$ & yes & transparent \\
\hline $0.7: 0.3: 2$ & 30 & $15.26 \pm 2.902$ & $\mathrm{a}$ & $0.156 \pm 0.032$ & $\mathrm{~b}$ & yes & transparent \\
\hline $0.8: 0.2: 2$ & 20 & $154.09 \pm 39.46$ & $\mathrm{~b}$ & $0.226 \pm 0.015$ & c & no & whitish \\
\hline $1: 0: 2$ & 0 & $383.3 \pm 63.50$ & $\mathrm{c}$ & $0.311 \pm 0.023$ & $\mathrm{~d}$ & no & white \\
\hline
\end{tabular}

${ }^{a} N=3$ replicates. ${ }^{b}$ For each column different letters indicate significant statistical differences $(P<0.05) .{ }^{c} \mathrm{SE}=\operatorname{standard}$ error $(\sigma / \sqrt{ } n)$.
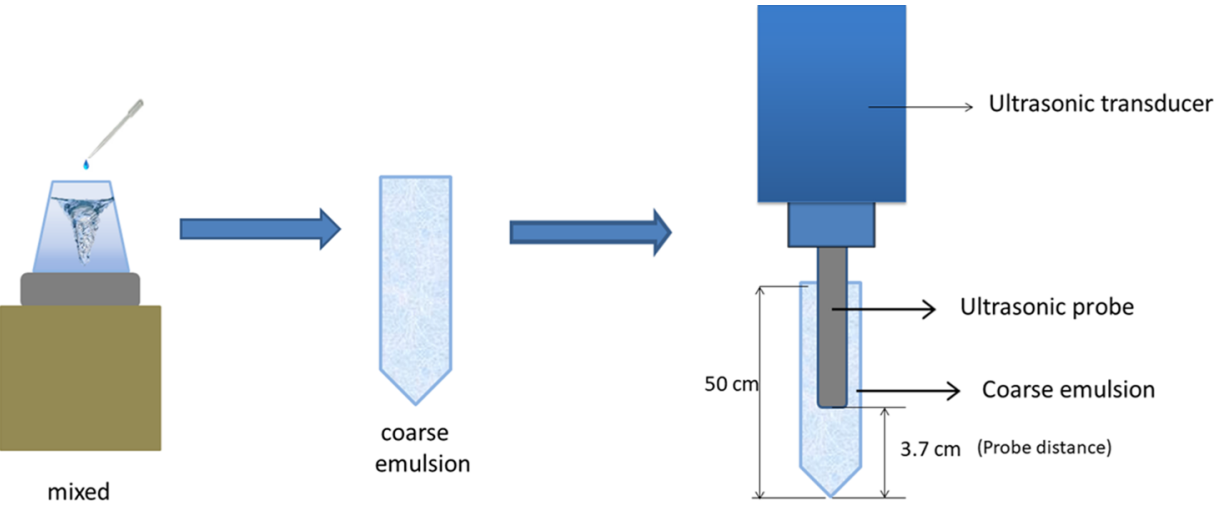

Figure 1. Schematic diagram of NE formation using ultrasound.

(1)
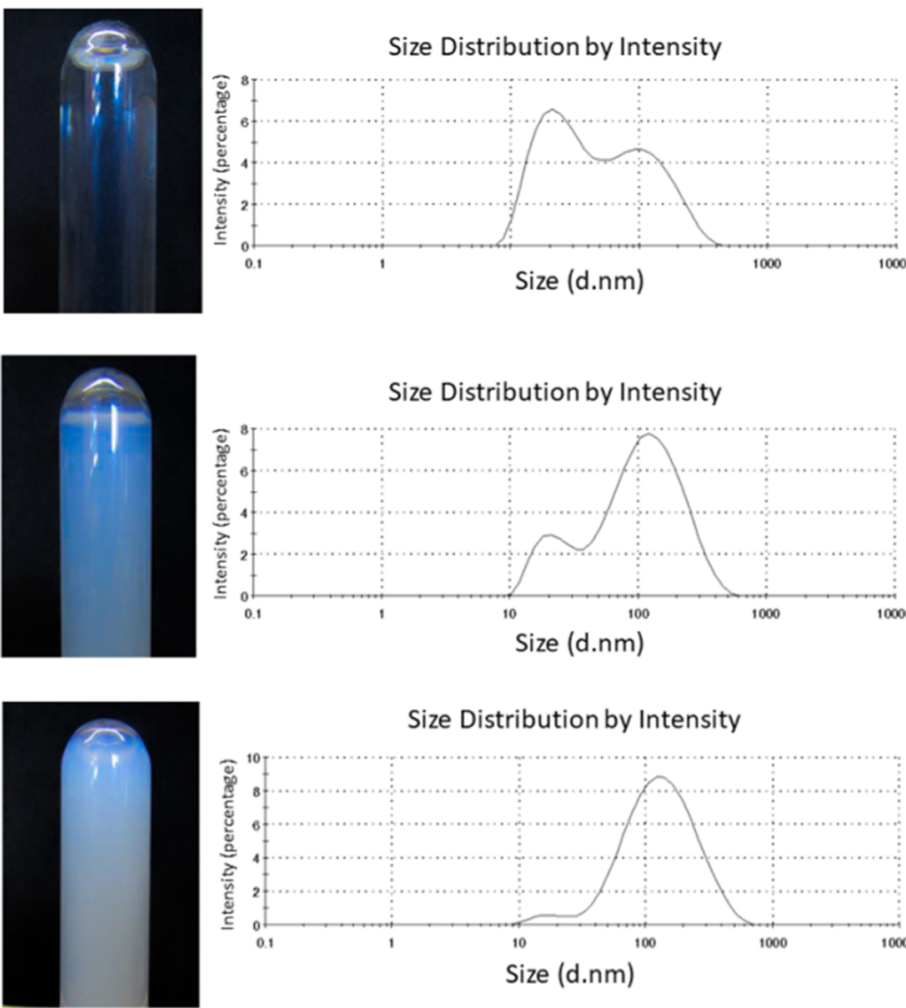

(2)
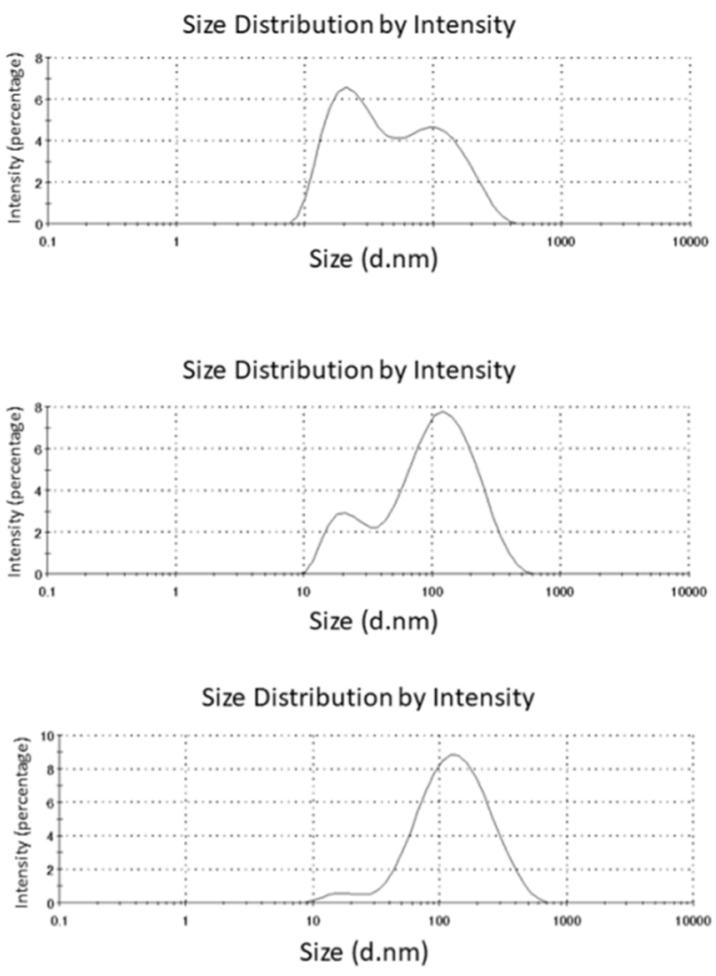

(3)
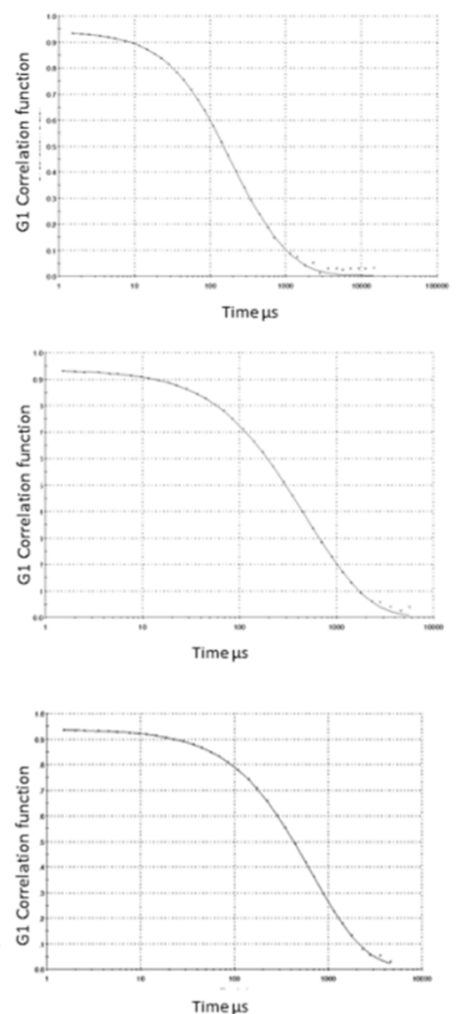

Figure 2. Visual appearance (column 1), size distribution (column 2), and autocorrelation function (column 3) of peppermint NEs.

values of the palmarosa + LA NEs are presented in Table 2, and their appearance and droplet size distribution are shown in Figure 3. Generally, in these NEs the droplet size decreases when the LA content is increased, affecting their macroscopic aspect. When the ratio of LA was increased by $20 \%$, the macroscopic aspect of the NEs was whitish and showed a droplet diameter of $223.3 \pm 50.59 \mathrm{~nm}$ and PDI values of 0.193 \pm 0.017 . Therefore, no significant differences were found between palmarosa alone and palmarosa $+20 \%$ LA system $(P$ $>0.05)$. When the ratio of LA was increased by 30 and $40 \%$, the palmarosa + LA NEs exhibited droplet sizes of $61.79 \pm$ 55.28 and $44.73 \pm 34.25 \mathrm{~nm}$, respectively, and both PDI values 
(1)
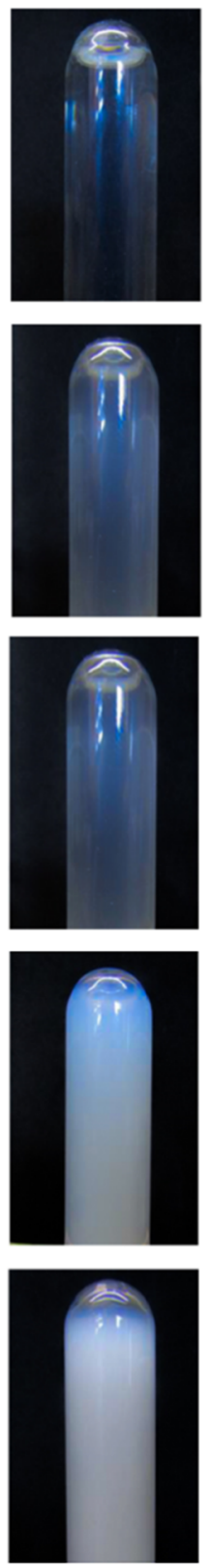

(2)

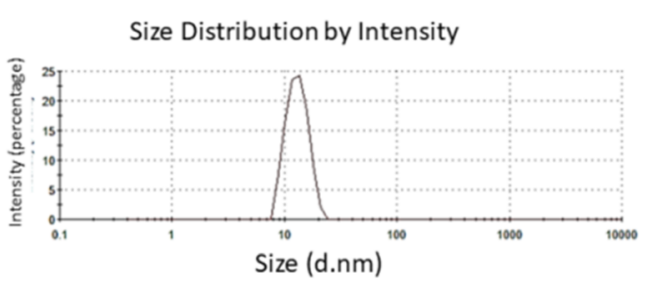

Size Distribution by Intensity

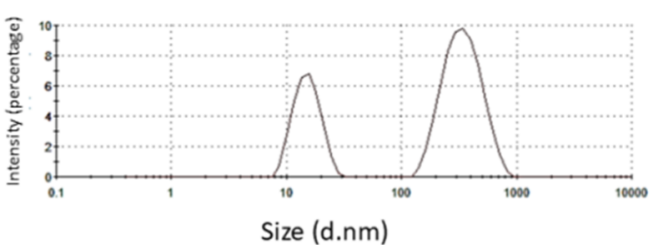

Size Distribution by Intensity

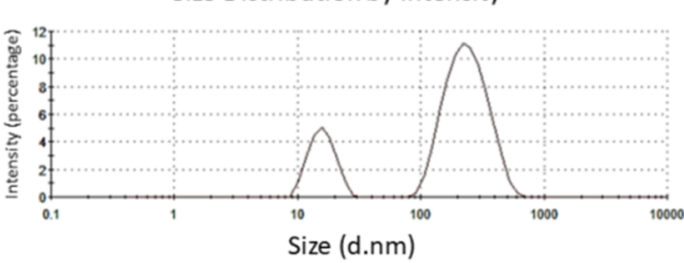

Size Distribution by Intensity

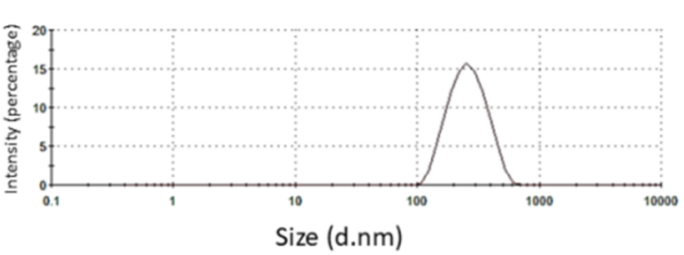

Size Distribution by Intensity

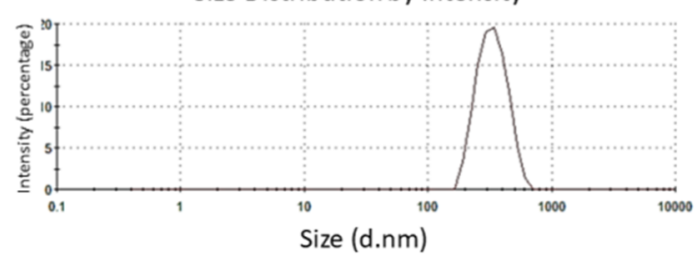

(3)
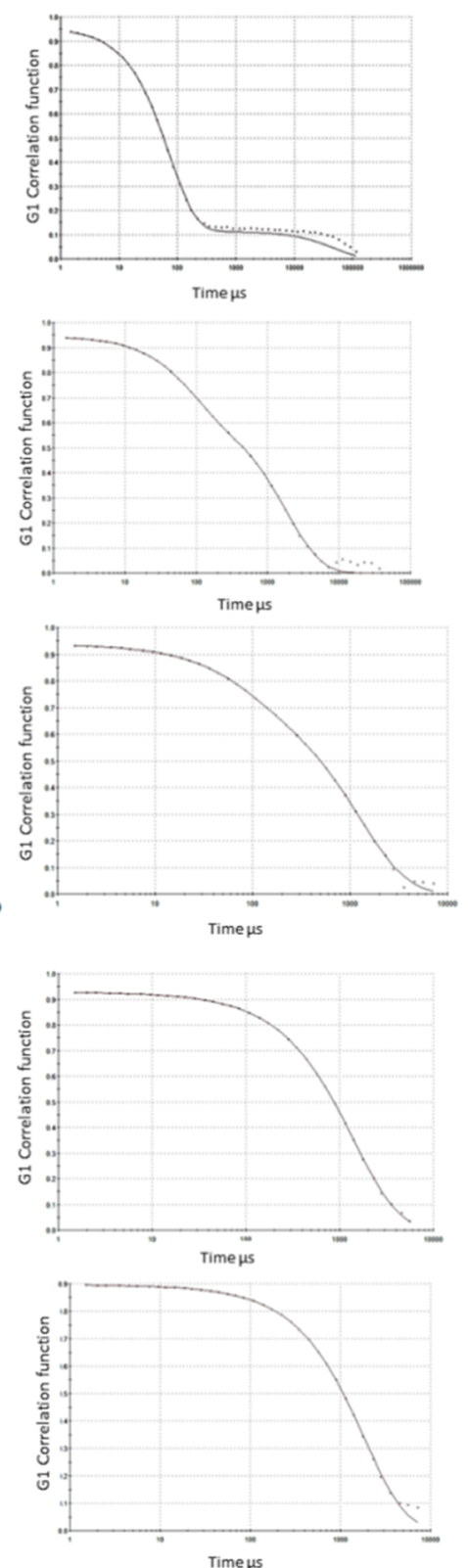

Figure 3. Visual appearance (column 1), size distribution (column 2), and autocorrelation function (column 3) of palmarosa EO + LA NEs.

were 1. Moreover, the visual appearances of the NEs were translucent. It is important to emphasize that both NEs (30 and 40\%) showed significant differences in the droplet size and the PDI values with palmarosa alone and palmarosa $+20 \% \mathrm{LA}$ $(P<0.05)$. These results showed the positive effect of LA on the stabilization of NEs. Finally, transparent NEs from palmarosa + LA were achieved using 50\% LA, and they showed the lowest droplet size $(P<0.05)$. The NEs measured $14.73 \pm 1.63 \mathrm{~nm}$ and their PDI values were $0.078 \pm 0.020$.

Once the NEs were stabilized, the Tween 80 concentration was decreased. Nevertheless, when the palmarosa + LA/Tween 80 ratios were $1: 1$ and $1: 1.5$, the NEs lost stability and the visual appearance was white.

Table 3 shows the stability of peppermint (ratios 1:2) and palmarosa + LA (ratios 0.5:0.5:2) NEs over time. For 30 days, peppermint showed no changes in the stability. On the first day, the NE size was $33.97 \pm 33.16$, and after 30 days their size was $70.10 \pm 33.95(P<0.05)$. For palmarosa NEs, no changes in the stability were observed for 120 days. On day 1, the NE size was $14.73 \pm 1.63$ and after 120 days their size was $18.01 \pm$ $3.65(P<0.05)$.

It is known that an increase in the surfactant concentration causes a decrease in particle size and we also observed this phenomenon in the present work. ${ }^{21,22,32}$ Basak and Guha ${ }^{33}$ demonstrated that the surfactant concentration in the aqueous solution is an important factor in the reduction of the droplet size. Generally, smaller droplet sizes lead to NEs with improved stability, which is an important factor for many commercial applications. ${ }^{34}$ Furthermore, Heydari et al. ${ }^{35}$ demonstrated that the droplet size of different peppermint 
(1)
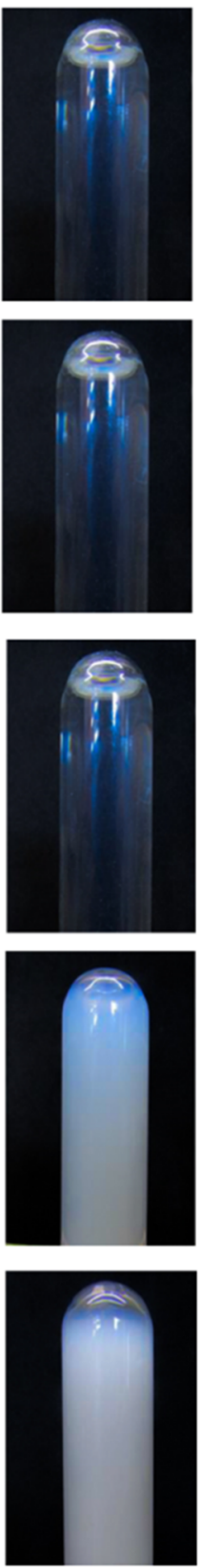

(2)
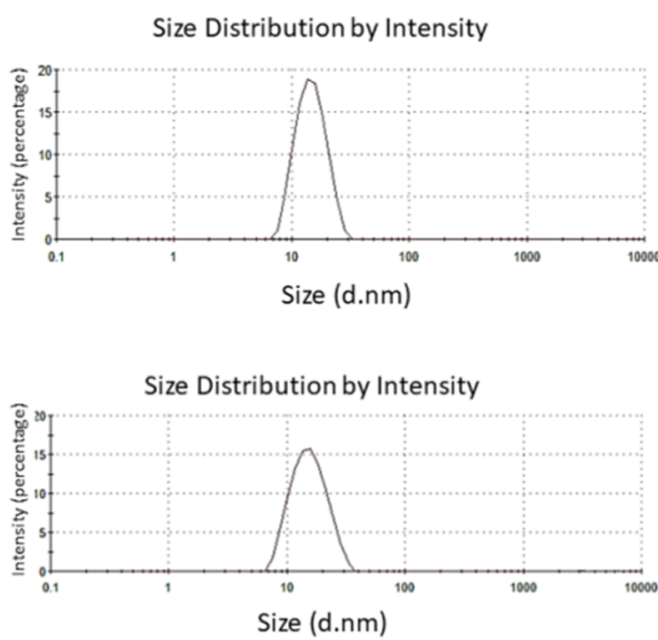

Size Distribution by Intensity

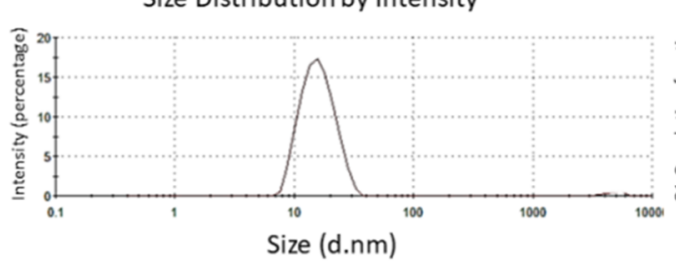

Size Distribution by Intensity

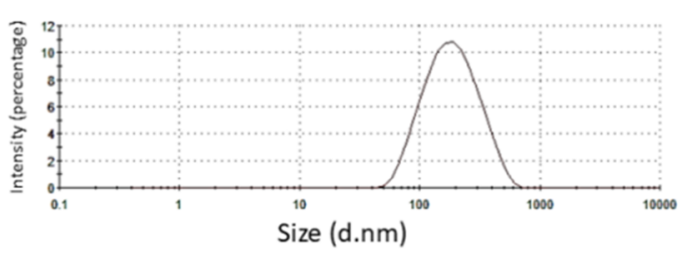

Size Distribution by Intensity

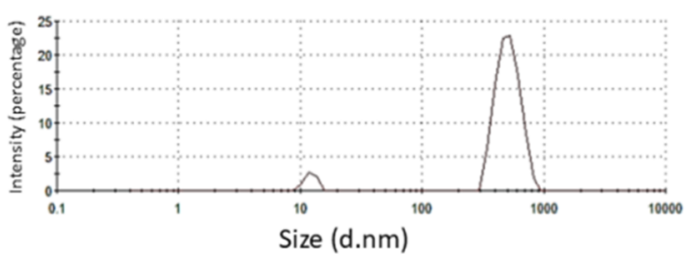

(3)
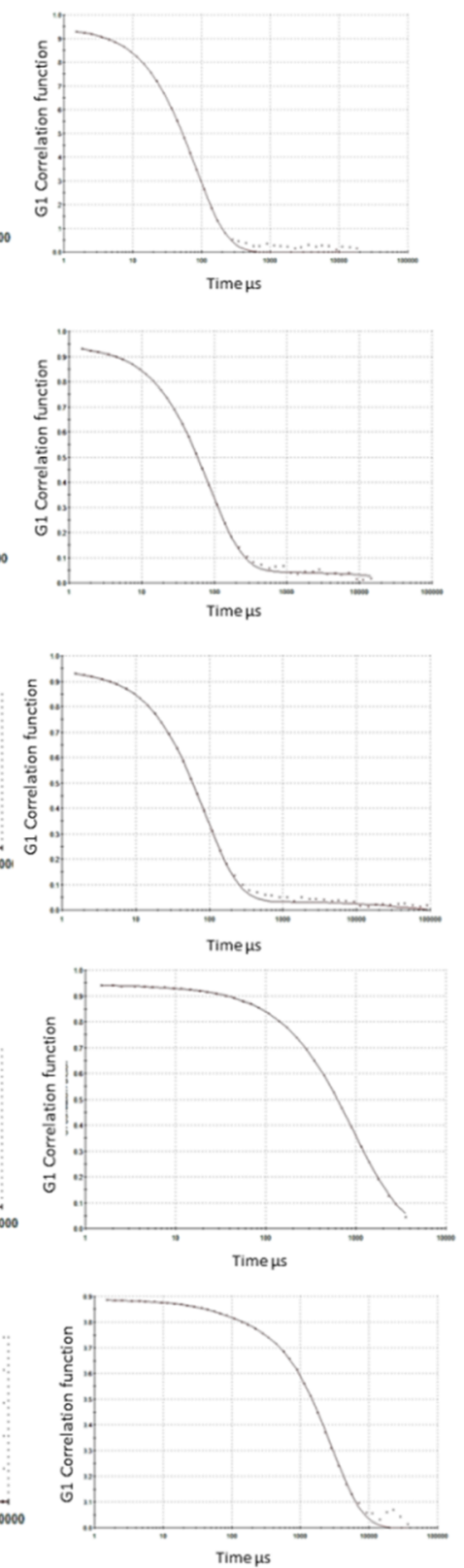

White

Figure 4. Visual appearance (column 1), size distribution (column 2), and autocorrelation function (column 3) of G + LA NEs.

formulations increases with the decrease of Tween 80 concentration. Moreover, it is known that the macroscopic aspect depends on the droplet size and its interaction with visible light. ${ }^{32,36}$ According to Salvia-Trujillo et al., ${ }^{37}$ the change in color is observed in the emulsions from white to transparent because of a reduction in the droplet diameter size, which is smaller than visible light. The size of peppermint and palmarosa NEs in our work is similar to the one reported by Barzegar et al. ${ }^{38}$ and smaller than the one informed by SalviaTrujillo et al., ${ }^{37}$ respectively.

Summarizing, peppermint (ratio 1:2) and palmarosa + LA (ratio 0.5:0.5:2) NEs were selected for the toxicological and ecotoxicological bioassays because of their small droplet size and stability.
LA: Role in Palmarosa Oil NE Formation. As mentioned previously, palmarosa EOs need the addition of LA in order to obtain stable NEs. G is the major compound of palmarosa oil (77\%). However, because of their hydrophobic properties, it is difficult to achieve an even dispersion in products with high water content. ${ }^{39}$ Moreover, some properties of NEs could be modified with the addition of different compounds. ${ }^{37}$ Therefore, we decided to study the influence of LA (a minor compound of palmarosa oil) in the stabilization of $G+L A$ NEs. Table 4 shows the physicochemical characteristics, and Figure 4 shows the DLS graphic and the visual appearance of $\mathrm{G}$ alone and combined with LA NEs. The $\mathrm{G}$ emulsion without LA presented a droplet size of $383.3 \pm 63.50$ and a PDI value of $0.311 \pm 0.023$, and its visual appearance was white. The emulsion of palmarosa oil alone showed values and macro- 


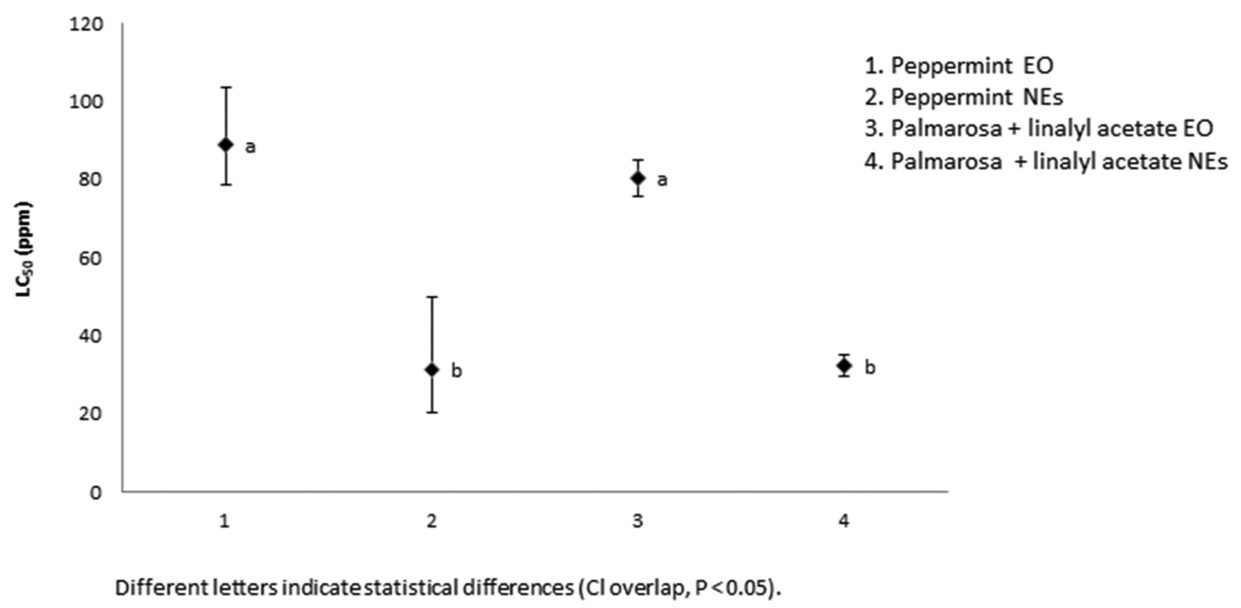

Figure 5. Biological activity of EOs and their NEs against fourth instar larvae of $C x p$. pipiens. $\mathrm{LC}_{50}$ values are expressed in ppm.

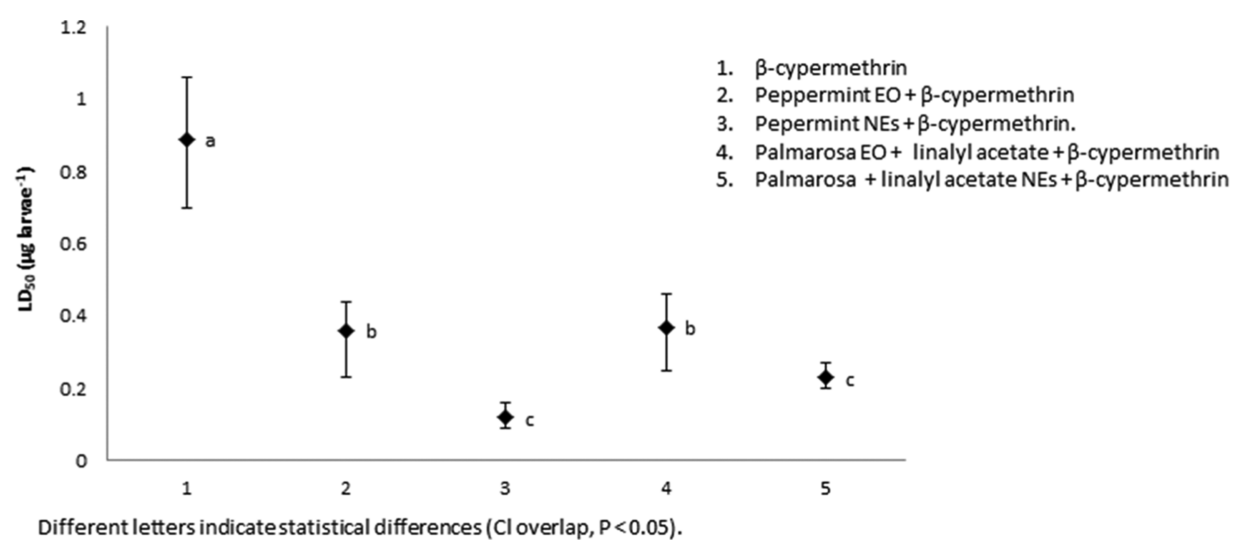

Figure 6. Biological activity of $\beta$ cypermethrin alone or combined with geranium EO and their NEs against fourth instar larvae of $P$. interpunctella. $\mathrm{LD}_{50}$ values are expressed in ug larvae ${ }^{-1}$.

scopic aspect similar to $G$ alone. When the systems were formed with $20 \%$ of LA, the droplet size was $154.09 \pm 39.46$, the PDi value was $0.226 \pm 0.015$, and the general appearance was whitish. Transparent NEs were obtained with 30, 40, and $50 \%$ of LA. These NEs showed similar droplet sizes, from 13.95 to $15.26 \mathrm{~nm}(P>0.05)$. However, significant differences were observed in the PDI values, and a lower value was obtained in the NEs with 50\% LA $(P<0.05)$.

Ziani et al. ${ }^{40}$ described different physicochemical phenomena that may act in the formation of stable NEs. First, the molecular characteristics of the oil compounds could be affected by mass transfer rate of molecules from emulsion droplets to surfactant micelles. Second, some oil molecules could act as cosurfactants that alter the optimum curvature of the surfactant monolayer and the optimum size of the micelle. Third, the possibility of the oil to be introduced into a surfactant micelle depends on its water solubility, conformation, and molecular weight. Consequently, the compounds with a relatively low molecular weight or a high water solubility tend to be present in the aqueous phase ( $\mathrm{G}$ molecular weight: $154.25 \mathrm{~g} / \mathrm{mol}$, water solubility: $100 \mathrm{mg} / \mathrm{L}$ at $25^{\circ} \mathrm{C}$ ). However, the compounds with a relatively high molecular weight or a low water solubility (LA molecular weight: $196.29 \mathrm{~g} / \mathrm{mol}$, water solubility: $8.2 \mathrm{mg} / \mathrm{L}$ at $25{ }^{\circ} \mathrm{C}$ ) tend to be incorporated into the hydrophobic interior of the micelle, improving the nanosystem stability. This idea could explain our observation where the increase in the G/LA ratio from 1:0 to $0.5: 0.5$ reduces the droplet diameter size. Similar physicochemical phenomena could be acting in the stabilization of palmarosa + LA NEs.

Bioassays. Figure 5 shows the $\mathrm{LC}_{50}$ values for $C x p$. pipiens larvae on exposure to peppermint $\mathrm{EO}$ and its NEs. For peppermint $\mathrm{EO}$, the $\mathrm{LC}_{50}$ value was $88.90 \mathrm{ppm}$ (78.68103.61), and for its NEs it was $31.24 \mathrm{ppm}$ (20.11-49.76). Therefore, the NEs enhanced the insecticidal activity 2.84 times. For palmarosa $\mathrm{EO}+\mathrm{LA}$, the $\mathrm{LC}_{50}$ value was $80.29 \mathrm{ppm}$ (75.58-84.71), and for their NEs it was $32.30 \mathrm{ppm}$ (29.7135.09). Consequently, NEs enhanced 2.48 times the insecticidal activity of palmarosa $\mathrm{EO}+\mathrm{LA}$.

$\beta$-Cypermethrin is an effective pyrethroid commonly used against many agricultural insect pests including $P$. interpunctella ${ }^{41}$. Figure 6 shows the insecticidal activity on $P$. interpunctella larvae using $\beta$-cypermethrin alone or EO (peppermint or palmarosa EO + LA) or NEs combined with $\beta$-cypermethrin. After $24 \mathrm{~h}$ of exposure, the $\mathrm{LD}_{50}$ value from $\beta$ cypermethrin was $0.89 \mu \mathrm{g} \mathrm{larvae}^{-1}(0.72-1.08)$. When the larvae were treated with peppermint $+\beta$-cypermethrin, the $\mathrm{LD}_{50}$ value was $0.36 \mu \mathrm{g}_{\text {larvae }}{ }^{-1}(0.28-0.49)$. The insecticidal activity of the peppermint $\mathrm{EO}+\beta$-cypermethrin was 2.47 times higher than the $\beta$-cypermethrin alone. Peppermint NEs $+\beta$-cypermethrin had $\mathrm{aLD}_{50}$ value of $0.12 \mu \mathrm{g}$ larvae ${ }^{-1}(0.07-$ $0.15)$. Mortality rates caused by peppermint NEs $+\beta$ cypermethrin were significantly higher than those recorded for $\beta$-cypermethrin alone (7.41 times). In addition, NEs 

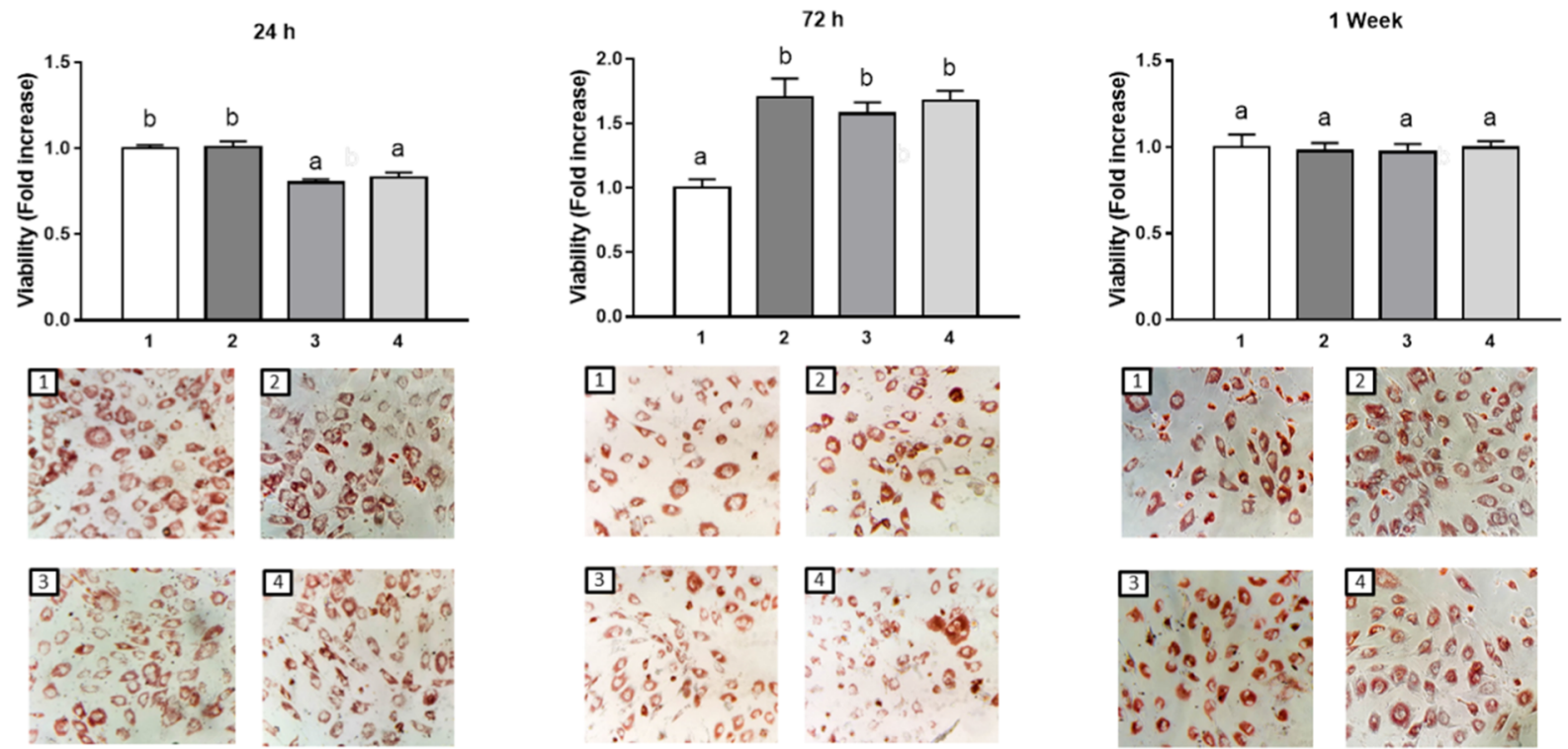

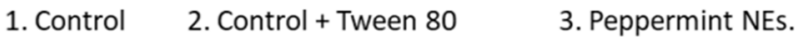

4. Palmarosa + linalyl acetate NEs

a Different letters indicate significant differences between treatments $(P<0.01)$.

Figure 7. Effects of peppermint and palmarosa + LA NEs in the cell viability after $24 \mathrm{~h}, 72 \mathrm{~h}$, and 1 week. The cell images (40d7) were captured using a $13 \mathrm{Mpx}$ camera and it illustrates the different treatments.

enhanced the insecticidal activity of peppermint $\mathrm{EO} 3.08$ times.

When the larvae were treated with palmarosa $\mathrm{EO}+\mathrm{LA}+\beta$ cypermethrin, the $\mathrm{LD}_{50}$ value was $0.37 \mu \mathrm{g}^{\text {larvae }}{ }^{-1}(0.28-$ $0.49)$. The $\mathrm{LD}_{50}$ value for palmarosa $\mathrm{EO}+\mathrm{LA} \mathrm{NEs}+\beta$ cypermethrin was found to be $0.23 \mu \mathrm{g} \mathrm{larvae}^{-1}(0.19-0.26)$. In particular, for palmarosa EO + LA NEs + $\beta$-cypermethrin showed a strong insecticidal activity with respect to the $\beta$ cypermethrin alone (3.78 times). Consequently, the NEs enhanced the insecticidal activity of the EO 1.56 times.

EOs are considered safe products, which have effects on metabolism, physiology, and the behavior of insects. ${ }^{42}$ Several works have suggested the inhibition of acetylcholinesterase and the block of the cholinergic, octopaminergic, and GABAergic system, as a possible mode of action of EOs. ${ }^{43-45}$ Moreover, different authors have demonstrated that EOs have insecticidal activity against $P$. interpunctella ${ }^{11}$ and $C x$ p. pipiens. ${ }^{46-48}$

Vatandoost et al. ${ }^{49}$ standardized larvicidal activity of EOs against mosquito larvae in different categories. Based on them, peppermint and palmarosa EOs could be classified as a moderately active larvicidal product. However, the NEs could be classified as active products by enhanced effect previously noted.

Gross et al. $^{50}$ and Joffe et al. ${ }^{51}$ demonstrated that EOs enhance the toxicity effects of some synthetic insecticides. The oil could increase the penetration of the synthetic insecticide and contribute to the inhibition of detoxified enzymatic systems. ${ }^{50}$ Besides a higher availability of the pyrethroid, it is possible when EOs (geranium, cinnamon, oregano, and clove) can interfere in the detoxification process. ${ }^{52}$ Probably, the EOs, in our research, work in a similar way.

In recent years, the use of nanotechnology in pest management has been increasing, and one of the most important goals is the preparation of ecofriendly nanopesticides. ${ }^{42}$ Our results have highlighted the good insecticidal activity of the NEs developed by ultrasound against $C x p$. pipiens and P. interpunctella. Currently, it is known that the nanosize of the droplet improves the ability of the EO to pass through the pores in the cuticle, which is a critical point in the insecticidal activity of any product. ${ }^{53}$ Moreover, the NEs increase the affinity between the EO particles and the target organism, and show several advantages, such as solubility and chemical stability. ${ }^{54}$

Ecotoxicology Assay. Generally, it is assumed that the ecotoxicity of bioinsecticides is related to the active ingredient mass concentration. Even though the nanoformulation containing bioinsecticides as an active ingredient must be considered as a different product as it shows novel unique properties, it would require a separate ecotoxicology assessment. ${ }^{55}$ Consequently, the ecotoxicology of the NEs was analyzed.

The results from the ecotoxicology assay in A. salina (aquatic model) showed that the $\mathrm{LC}_{50}$ value from peppermint and palmarosa + LA NEs was $63.96 \mathrm{ppm}(61.26-67.01)$ and 42.57 ppm (40.26-44.68), respectively. These $\mathrm{LC}_{50}$ values were significantly higher than the $\mathrm{LC}_{50}$ values from $C x p$. pipiens $(P$ $<0.05)$. The combined effects of the NEs and $\beta$-cypermethrin were also analyzed in T. molitor (terrestrial model). For peppermint NEs combined with $\beta$-cypermethrin, the $\mathrm{LC}_{50}$ value was $0.016 \mu \mathrm{g} \mathrm{larvae}^{-1}(0.003-0.025)$, and for palmarosa + LA NEs combined with $\beta$-cypermethrin, the $\mathrm{LC}_{50}$ value was $0.019(0.006-0.030)$. These results did not show significant differences between the NEs and the control assay $\left(\mathrm{LC}_{50}=\right.$ $0.025, \mathrm{CI}=0.021-0.029)$. Our results showed that the NEs can still be considered relatively safe for these nontarget organisms.

The basic principle involved in the nanoformulation development of insecticides was the general agreement that they possess better environmental safety properties as these products reduce the active ingredient concentration applied. However, the nanoformulation tends to produce a slow release of this active ingredient, which implies a longer exposure of the 
product to the environment and consequently, a higher risk for beneficial and nontarget organisms. ${ }^{56}$ There is little research focused on the biosafety evaluation of nanoinsecticides based on botanical products. However, Oliveira et al. ${ }^{57,58}$ analyzed the effect of solid lipic nanoparticles of pyrethrum extract on anuran amphibians and honeybees, and demonstrated that they are relatively safe for these nontarget organisms.

On the other hand, the ecological risk assessment of the EO alone showed discordant results. Some authors showed negative effects of the EO on Daphinia magna Straus (Cladocera, Daphniidae), ${ }^{59-61}$ whereas Pavela and Govindarajan $^{62}$ and Pavela ${ }^{63}$ demonstrated that some EOs could be relatively friendly to nontarget organisms and the environment. In this sense, our work shows that the NEs are relatively safe for nontarget organisms, such as A. salina and T. molitor.

Cell Culture and Viability. In the context of the biosafety evaluation of these novel nanofomulations, the viability of cell culture exposed to peppermint and palmarosa + LA NEs was evaluated. After $24 \mathrm{~h}$, the treated cells with NEs showed a significant slowdown on the cell growth rate $(P<0.01)$ (Figure $7)$. However, after $72 \mathrm{~h}$, osteoblasts exposed to Tween 80 and NEs exhibited a significant increase in the cell viability rate compared with the control cells $(P<0.01)$ (Figure 7$)$. After 1 week, the NEs did not show a significant effect on the cell viability when compared with control and control + Tween 80 . The enhanced cell viability promoted by the control + surfactant and NEs after $72 \mathrm{~h}$ of exposure could be explained taking into account the work of Taoka et al., ${ }^{64}$ which showed that Tween 80 increases the cell membrane permeability and enhances the nutritional input from the medium into the cell.

It is important to emphasize the fact that there is lack of information about the cytotoxicity effects of NEs loaded with EOs. Da Silva et al. ${ }^{65}$ found that Basil NEs did not cause a reduction of cell viability with doses from 100 to $6000 \mathrm{ppm}$. $\mathrm{Li}$ et al. ${ }^{65}$ formulated a nanosystem based on Tween $80 /$ ethanol/ water and Cymbopogon citrus EO, and found little toxicity against human cells. ${ }^{66}$ Nevertheless, Nuchuchua et al. ${ }^{67}$ worked with NEs based on citronella, hairy basil, and vetiver oil, and demonstrated the cytotoxic effect against fibroblast cells depending on the doses. Moreover, neem oil NEs were found to be toxic in lymphocyte cells. ${ }^{68}$ Our results confirm that peppermint and palmarosa + LA NEs are safe and do not affect the cell viability.

\section{CONCLUSIONS}

The potential uses of NEs based on EOs as novel bioinsecticides responds to the new socioproductive conditions and fulfill the demands of new ecofriendly pest management tools. This study focused on the optimization and characterization of peppermint and palmarosa + lynaly acetate NEs assisted by ultrasound. All the NEs were elaborated in the same ultrasound conditions (power $=65 \mathrm{~W}$ time $=2 \mathrm{~min}$ cycles $=30$ on/20 off). The peppermint NEs were formed using a 1:2 EO/ Tween 80 ratio and were stable for 30 days. The palmarosa NEs used 0.5:0.5:2 EO/LA/Tween 80 ratio and were stable for 120 days. The NEs also enhanced the insecticidal effect of peppermint and palmarosa EO, on $C x$ p p pipiens 2.48 and 2.84 times, respectively, and 3.08 and 1.56 times on $P$. interpunctella. The successful implementation of the NEs as new insecticides requires that they do not produce a toxic effect for nontarget organisms. The peppermint and palmarosa + LA NEs did not have a toxicity effect on $A$. salina and T. molitor. Moreover, after 3 and 7 days, the viability on mammalian cell culture models was not affected by NEs.

\section{AUTHOR INFORMATION}

\section{Corresponding Author}

Jorge Omar Werdin-González - Laboratorio de Zoología de Invertebrados II, Departamento de Biologia, Bioquimica y Farmacia, Universidad Nacional del Sur, B8000CPB, Buenos Aires, Argentina; INQUISUR, Departamento de Quimica, Universidad Nacional del Sur (UNS)-CONICET, 8000, Buenos Aires, Argentina; (1) orcid.org/0000-0001-5152-3782; Email: jwerdin@hotmail.com

\section{Authors}

Emiliano Jesser - INBIOSUR, Departamento de Biologia, Bioquimica y Farmacia, Universidad Nacional del Sur (UNS)CONICET, B8000CPB, Buenos Aires, Argentina; Laboratorio de Zoologia de Invertebrados II, Departamento de Biologia, Bioquimica y Farmacia, Universidad Nacional del Sur, B8000CPB, Buenos Aires, Argentina

Cristhian Yeguerman - Laboratorio de Zoologia de Invertebrados II, Departamento de Biologia, Bioquimica y Farmacia, Universidad Nacional del Sur, B8000CPB, Buenos Aires, Argentina

Valeria Gili - INBIOSUR, Departamento de Biologia, Bioquimica y Farmacia, Universidad Nacional del Sur (UNS)CONICET, B8000CPB, Buenos Aires, Argentina

Graciela Santillan - INBIOSUR, Departamento de Biología, Bioquimica y Farmacia, Universidad Nacional del Sur (UNS)CONICET, B8000CPB, Buenos Aires, Argentina

Ana Paula Murray - INQUISUR, Departamento de Quimica, Universidad Nacional del Sur (UNS)-CONICET, 8000, Buenos Aires, Argentina

Claudia Domini - INQUISUR, Departamento de Quimica, Universidad Nacional del Sur (UNS)-CONICET, 8000, Buenos Aires, Argentina

Complete contact information is available at: https://pubs.acs.org/10.1021/acssuschemeng.0c02224

\section{Author Contributions}

E.J.: Conceptualization, Methodology, Formal analysis, Investigation, Writing-Original Draft. C.Y.: Methodology, Formal analysis, Investigation, Writing-Review \& Editing. V.G.: Methodology, Formal analysis, Investigation, Writing-Review \& Editing. G.S.: Supervision, Funding acquisition, WritingReview \& Editing. A.P.M.: Supervision, Funding acquisition, Writing-Review \& Editing. C.D.: Writing-Original Draft, Supervision, Funding acquisition. J.O.W.-G.: Writing-Original Draft, Supervision, Funding acquisition, Project administration.

\section{Notes}

The authors declare no competing financial interest.

\section{ACKNOWLEDGMENTS}

This research was supported by Grants PGI 24/B277, 24/ B274, 24/B255, and 24/Q099 from UNS; PICT-2015-2537 and PICT-2017-1443 from ANPCyT (Agencia Nacional de Promoción Científica y Tecnológica); PIP $11220130100307 \mathrm{CO}$ from CONICET (Consejo Nacional de Investigaciones Cientificas y Técnicas). 


\section{REFERENCES}

(1) Wu, X.; Lu, Y.; Zhou, S.; Chen, L.; Xu, B. Impact of climate change on human infectious diseases: Empirical evidence and human adaptation. Environ. Int. 2016, 86, 14-23.

(2) Samy, A. M.; Elaagip, A. H.; Kenawy, M. A.; Ayres, C. F.; Peterson, A. T.; Soliman, D. E. Climate change influences on the global potential distribution of the mosquito Culex quinquefasciatus, vector of West Nile virus and lymphatic filariasis. PLoS One 2016, 11, No. e0163863.

(3) Sanei-Dehkordi, A.; Gholami, S.; Abai, M. R.; Sedaghat, M. M. Essential oil composition and larvicidal evaluation of Platycladus orientalis against two Mosquito Vectors, Anopheles stephensi and Culex pipiens. J. Arthropod-Borne Dis. 2018, 12, 101-107.

(4) Gopalakrishnan, R., Veer, V. Bioecology, Insecticide Susceptibility and Management of Culex quinquefasciatus Say, 1823: A Major Vector of Lymphatic Filariasis in India. In Lymphatic Filariasis; Tyagi, B., Ed.; Springer: Singapore, 2018, pp 199-210.

(5) Hasegawa, T.; Fujimori, S.; Havlík, P.; Valin, H.; Bodirsky, B. L.; Doelman, J. C.; Fellmann, T.; Kyle, P.; Koopman, J. F. L.; LotzeCampen, H.; Mason-D'Croz, D.; Ochi, Y.; Pérez Domínguez, I.; Stehfest, E.; Sulser, T. B.; Tabeau, A.; Takahashi, K.; Takakura, J. y.; van Meijl, H.; van Zeist, W.-J.; Wiebe, K.; Witzke, P. Risk of increased food insecurity under stringent global climate change mitigation policy. Nat. Clim. Change 2018, 8, 699-703.

(6) Mohapatra, D.; Kar, A.; Giri, S. K. Insect pest management in stored pulses: an overview. Food Bioprocess Technol. 2014, 8, 239265.

(7) Montagna, M.; Mereghetti, V.; Gargari, G.; Guglielmetti, S.; Faoro, F.; Lozzia, G.; Locatelli, D.; Limonta, L. Evidence of a bacterial core in the stored products pest Plodia interpunctella: the influence of different diets. Environ. Microbiol. 2016, 18, 4961-4973.

(8) Fouad, H.; Hongiie, L.; Hosni, D.; Wei, J.; Abbas, G.; Ga'al, H.; Jianchu, M. Controlling Aedes albopictus and Culex pipiens pallens using silver nanoparticles synthesized from aqueous extract of Cassia fistula fruit pulp and its mode of action. Artif. Cells, Nanomed., Biotechnol. 2017, 46, 558-567.

(9) Govindarajan, M.; Rajeswary, M.; Benelli, G. Chemical composition, toxicity and non-target effects of Pinus kesiya essential oil: an eco-friendly and novel larvicide against malaria, dengue and lymphatic filariasis mosquito vectors. Ecotoxicol. Environ. Saf. 2016, $129,85-90$.

(10) Benelli, G.; Pavela, R.; Giordani, C.; Casettari, L.; Curzi, G.; Cappellacci, L.; Petrelli, R.; Maggi, F. Acute and sub-lethal toxicity of eight essential oils of commercial interest against the filariasis mosquito Culex quinquefasciatus and the housefly Musca domestica. Ind. Crops Prod. 2018, 112, 668-680.

(11) Jesser, E. N.; Werdin-González, J. O.; Murray, A. P.; Ferrero, A. A. Efficacy of essential oils to control the Indian meal moth, Plodia interpunctella (Hübner) (Lepidoptera: Pyralidae). J. Asia-Pac. Entomol. 2017, 20, 1122-1129.

(12) Olufemi-Salami, F. K.; Akinneye, J. O.; Salami, O. S. Contact and Fumigant Toxicity of Uvaria afzelli (Scott) against Plodia interpunctella (Hubner) Infesting Maize Grains in Nigeria. Jordan J. Biol. Sci. 2018, 12, 49-53.

(13) Pavela, R.; Benelli, G.; Pavoni, L.; Bonacucina, G.; Cespi, M.; Cianfaglione, K.; Bajalan, I.; Morshedloo, M. R.; Lupidi, G.; Romano, D.; Canale, A.; Maggi, F. Microemulsions for delivery of Apiaceae essential oils-Towards highly effective and eco-friendly mosquito larvicides? Ind. Crops Prod. 2019, 129, 631-640.

(14) Smith, A. M.; Gilbertson, L. M. Rational ligand design to improve agrochemical delivery efficiency and advance agriculture sustainability. ACS Sustainable Chem. Eng. 2018, 6, 13599-13610.

(15) Jemaa, M. B.; Falleh, H.; Serairi, R.; Neves, M. A.; Snoussi, M.; Isoda, H.; Ksouri, R. Nanoencapsulated Thymus capitatus essential oil as natural preservative. Innovative Food Sci. Emerging Technol. 2017, 45, 92-97.

(16) Mehmood, T.; Ahmed, A.; Ahmed, Z.; Ahmad, M. S. Optimization of soya lecithin and Tween 80 based novel vitamin D nanoemulsions prepared by ultrasonication using response surface methodology. Food Chem. 2019, 289, 664-670.

(17) Homs, M.; Calderó, G.; Monge, M.; Morales, D.; Solans, C. Influence of polymer concentration on the properties of nanoemulsions and nanoparticles obtained by a low-energy method. Colloids Surf., A 2018, 536, 204-212.

(18) Parthasarathy, S.; Siah Ying, T.; Manickam, S. Generation and optimization of palm oil-based oil-in-water $(\mathrm{O} / \mathrm{W})$ submicronemulsions and encapsulation of curcumin using a liquid whistle hydrodynamic cavitation reactor (LWHCR). Ind. Eng. Chem. Res. 2013, 52, 11829-11837.

(19) Raviadaran, R.; Ng, M. H.; Manickam, S.; Chandran, D. Ultrasound-assisted water-in-palm oil nano-emulsion: Influence of polyglycerol polyricinoleate and $\mathrm{NaCl}$ on its stability. Ultrason. Sonochem. 2019, 52, 353-363.

(20) Raviadaran, R.; Chandran, D.; Shin, L. H.; Manickam, S. Optimization of palm oil in water nano-emulsion with curcumin using microfluidizer and response surface methodology. LWT-Food Sci. Technol. 2018, 96, 58-65.

(21) Moghimi, R.; Aliahmadi, A.; Rafati, H. Ultrasonic nanoemulsification of food grade trans-cinnamaldehyde: 1, 8-Cineol and investigation of the mechanism of antibacterial activity. Ultrason. Sonochem. 2017, 35, 415-421.

(22) Periasamy, V. S.; Athinarayanan, J.; Alshatwi, A. A. Anticancer activity of an ultrasonic nanoemulsion formulation of Nigella sativa L. essential oil on human breast cancer cells. Ultrason. Sonochem. 2016, 31, 449-455.

(23) Govindarajan, M.; Benelli, G. Facile biosynthesis of silver nanoparticles using Barleria cristata: mosquitocidal potential and biotoxicity on three non-target aquatic organisms. Parasitol. Res. 2016, $115,925-935$.

(24) Kovendan, K.; Chandramohan, B.; Dinesh, D.; Abirami, D.; Vijayan, P.; Govindarajan, M.; Vincent, S.; Benelli, G. Greensynthesized silver nanoparticles using Psychotria nilgiriensis: toxicity against the dengue vector Aedes aegypti (Diptera: Culicidae) and impact on the predatory efficiency of the non-target organism Poecilia sphenops (Cyprinodontiformes: Poeciliidae). J. Asia Pac. Entomol. 2016, 19, 1001-1007.

(25) Mishra, P.; Dutta, S.; Haldar, M.; Dey, P.; Kumar, D.; Mukherjee, A.; Chandrasekaran, N. Enhanced mosquitocidal efficacy of colloidal dispersion of pyrethroid nanometric emulsion with benignity towards non-target species. Ecotoxicol. Environ. Saf. 2019, 176, 258-269.

(26) Bondarenko, O.; Juganson, K.; Ivask, A.; Kasemets, K.; Mortimer, M.; Kahru, A. Toxicity of $\mathrm{Ag}, \mathrm{CuO}$ and $\mathrm{ZnO}$ nanoparticles to selected environmentally relevant test organisms and mammalian cells in vitro: a critical review. Arch. Toxicol. 2013, 87, 1181-1200.

(27) Gomes, S. I. L.; Scott-Fordsmand, J. J.; Campos, E. V. R.; Grillo, R.; Fraceto, L. F.; Amorim, M. J. B. On the safety of nanoformulations to non-target soil invertebrates-an atrazine case study. Environ. Sci. Nano. 2019, 6, 1950-1958.

(28) Novak, S.; Drobne, D.; Menard, A. Prolonged feeding of terrestrial isopod (Porcellio scaber, Isopoda, Crustacea) on $\mathrm{TiO} 2$ nanoparicles. Absence of toxic effect. ZooKeys 2012, 176, 261-273.

(29) Jesser, E.; Lorenzetti, A. S.; Yeguerman, C.; Murray, A. P.; Domini, C.; Werdin-González, J. O. Ultrasound assisted formation of essential oil nanoemulsions: Emerging alternative for Culex pipiens pipiens Say (Diptera: Culicidae) and Plodia interpunctella Hübner (Lepidoptera: Pyralidae) management. Ultrason. Sonochem. 2020, 61, 104832.

(30) World Health Organization. Guidelines for Laboratory and Fieldtesting of Mosquito Larvicides, 2005; WHO/CDS/WHOPES/ GCDPP/2005.13.

(31) Katz, S.; Boland, R.; Santillán, G. Purinergic (ATP) signaling stimulates JNK1 but not JNK2 MAPK in osteoblast-like cells: contribution of intracellular $\mathrm{Ca} 2+$ release, stress activated and $\mathrm{L}$ voltage-dependent calcium influx, PKC and Src kinases. Arch. Biochem. Biophys. 2008, 477, 244-252. 
(32) Saani, S. M.; Abdolalizadeh, J.; Heris, S. Z. Ultrasonic/ sonochemical synthesis and evaluation of nanostructured oil in water emulsions for topical delivery of protein drugs. Ultrason. Sonochem. 2019, 55, 86-95.

(33) Basak, S.; Guha, P. Betel leaf (Piper betle L.) essential oil microemulsion: Characterization and antifungal activity on growth, and apparent lag time of Aspergillus flavus in tomato paste. $L W T-$ Food Sci. Technol. 2017, 75, 616-623.

(34) Yang, Y.; Zhao, C.; Chen, J.; Tian, G.; McClements, D. J.; Xiao, H.; Zheng, J. Encapsulation of polymethoxyflavones in citrus oil emulsion-based delivery systems. J. Agric. Food Chem. 2017, 65, $1732-1739$

(35) Heydari, M.; Amirjani, A.; Bagheri, M.; Sharifian, I.; Sabahi, Q. Eco-friendly pesticide based on peppermint oil nanoemulsion: preparation, physicochemical properties, and its aphicidal activity against cotton aphid. Environ. Sci. Pollut. Res. 2019, 27, 6667-6679.

(36) Radi, M.; Akhavan-Darabi, S.; Akhavan, H. R.; Amiri, S. The use of orange peel essential oil microemulsion and nanoemulsion in pectin-based coating to extend the shelf life of fresh-cut orange. $J$. Food Process. Preserv. 2018, 42, e13441.

(37) Salvia-Trujillo, L.; Rojas-Graü, A.; Soliva-Fortuny, R.; MartínBelloso, R.; Martín-Belloso, O. Physicochemical characterization and antimicrobial activity of food-grade emulsions and nanoemulsions incorporating essential oils. Food Hydrocolloids 2015, 43, 547-556.

(38) Barzegar, H.; Mehrnia, M. A.; Nasehi, B.; Alipour, M. Fabrication of peppermint essential oil nanoemulsions by spontaneous method: effect of preparing conditions on droplet size. Flavour Fragrance J. 2018, 33, 351-356.

(39) Balta, I.; Brinzan, L.; Stratakos, A. C.; Linton, M.; Kelly, C.; Pinkerton, L.; Corcionivoschi, N. Geraniol and linalool loaded nanoemulsions and their antimicrobial activity. Bull. Univ. Agric. Sci. Vet. Med. Cluj-Napoca - Anim. Sci. Biotechnol. 2017, 74, 157-161.

(40) Ziani, K.; Fang, Y.; McClements, D. J. Fabrication and stability of colloidal delivery systems for flavor oils: Effect of composition and storage conditions. Food Res. Int. 2012, 46, 209-216.

(41) Andric, G.; Kljajic, P.; Prazic-Golic, M. Residual efficacy of cypermethrin and pirimiphos-methyl against Sitophilus granarius (L.) and Plodia interpunctella (Hübner) on concrete surface. Pestic Phytomed 2014, 29, 275-281.

(42) de Oliveira, J. L.; Campos, E. V. R.; Fraceto, L. F. Recent Developments and Challenges for Nanoscale Formulation of Botanical Pesticides for Use in Sustainable Agriculture. J. Agric. Food Chem. 2018, 66, 8898-8913.

(43) Gaire, S.; Scharf, M. E.; Gondhalekar, A. D. Toxicity and neurophysiological impacts of plant essential oil components on bed bugs (Cimicidae: Hemiptera). Sci. Rep. 2019, 9, 3961.

(44) Pavela, R.; Benelli, G. Essential oils as ecofriendly biopesticides? Challenges and constraints. Trends Plant Sci. 2016, 21, 1000-1007.

(45) Upadhyay, N.; Dwivedy, A. K.; Kumar, M.; Prakash, B.; Dubey, N. K. Essential oils as eco-friendly alternatives to synthetic pesticides for the control of Tribolium castaneum (Herbst)(Coleoptera: Tenebrionidae). J. Essent. Oil-Bear. Plants 2018, 21, 282-297.

(46) Montefuscoli, A. R.; Werdin González, J. O.; Palma, S. D.; Ferrero, A. A.; Fernández Band, B. Design and development of aqueous nanoformulations for mosquito control. Parasitol. Res. 2014, 113, 793-800.

(47) Pavela, R. Acute toxicity and synergistic and antagonistic effects of the aromatic compounds of some essential oils against Culex quinquefasciatus Say larvae. Parasitol. Res. 2015, 114, 3835-3853.

(48) Sanei-Dehkordi, A.; Soleimani-Ahmadi, M.; Abadi, Y. S.; Paksa, A. Wild chive oil is an extremely effective larvicide against malaria mosquito vector Anopheles stephensi. Asian Pac. J. Trop. Med. 2019, 12 , $170-174$.

(49) Vatandoost, H.; Sanei Dehkordi, A.; Sadeghi, S. M. T.; Davari, B.; Karimian, F.; Abai, M. R.; Sedaghat, M. M. Identification of chemical constituents and larvicidal activity of Kelussia odoratissima Mozaffarian essential oil against two mosquito vectors Anopheles stephensi and Culex pipiens (Diptera: Culicidae). Exp. Parasitol. 2012, 132, 470-474.
(50) Gross, A. D.; Norris, E. J.; Kimber, M. J.; Bartholomay, L. C.; Coats, J. R. Essential oils enhance the toxicity of permethrin against Aedes aegypti and Anopheles gambiae. Med. Vet. Entomol. 2017, 31, 55-62.

(51) Joffe, T.; Gunning, R. V.; Allen, G. R.; Kristensen, M.; Alptekin, S.; Field, L. M.; Moores, G. D. Investigating the potential of selected natural compounds to increase the potency of pyrethrum against houseflies Musca domestica (Diptera: Muscidae). Pest Manag. Sci. 2012, 68, 178-184.

(52) Norris, E. J.; Gross, A. D.; Bartholomay, L. C.; Coats, J. R. Plant essential oils synergize various pyrethroid insecticides and antagonize malathion in Aedes aegypti. Med. Vet. Entomol. 2019, 33, 453.

(53) Osanloo, M.; Amani, A.; Sereshti, H.; Abai, M. R.; Esmaeili, F.; Sedaghat, M. M. Preparation and optimization nanoemulsion of Tarragon (Artemisia dracunculus) essential oil as effective herbal larvicide against Anopheles stephensi. Ind. Crops Prod. 2017, 109, 214-219.

(54) Shahzad, K.; Manzoor, F. Nanoformulations and their mode of action in insects: a review of biological interactions. Drug Chem. Toxicol. 2019, 1, 1-11.

(55) Sun, C.; Verheggen, F.; Zeng, Z.; Cui, H. Polymer-Based Nanoinsecticides: Current Developments, Environmental Risks and Future Challenges-A Review. Biotechnol. Agron. Soc. Environ. 2020, 24, $59-69$.

(56) de Oliveira, J. L.; Campos, E. V. R.; Bakshi, M.; Abhilash, P. C.; Fraceto, L. F. Application of nanotechnology for the encapsulation of botanical insecticides for sustainable agriculture: prospects and promises. Biotechnol. Adv. 2014, 32, 1550-1561.

(57) Oliveira, C. R.; Domingues, C. E. C.; de Melo, N. F. S.; Roat, T. C.; Malaspina, O.; Jones-Costa, M.; Silva-Zacarin, E. C. M.; Fraceto, L. F. Nanopesticide based on botanical insecticide pyrethrum and its potential effects on honeybees. Chemosphere 2019, 236, 124282.

(58) Oliveira, C. R.; Garcia, T. D.; Franco-Belussi, L.; Salla, R. F.; Souza, B. F. S.; de Melo, N. F. S.; Irazusta, S. P.; Jones-Costa, M.; Silva-Zacarin, E. C. M.; Fraceto, L. F. Pyrethrum extract encapsulated in nanoparticles: Toxicity studies based on genotoxic and hematological effects in bullfrog tadpoles. Environ. Pollut. 2019, 253, 1009-1020.

(59) Conti, B.; Flamini, G.; Cioni, P. L.; Ceccarini, L.; Macchia, M.; Benelli, G. Mosquitocidal essential oils: are they safe against nontarget aquatic organisms? Parasitol. Res. 2014, 113, 251-259.

(60) Park, H.-M.; Kim, J.; Chang, K.-S.; Kim, B.-S.; Yang, Y.-J.; Kim, G.-H.; Shin, S.-C.; Park, I.-K. Larvicidal activity of Myrtaceae essential oils and their components against Aedes aegypti, acute toxicity on Daphnia magna, and aqueous residue. J. Med. Entomol. 2011, 48, 405-410.

(61) Seo, S.-M.; Park, H.-M.; Park, I.-K. Larvicidal activity of Ajowan (Trachyspermum ammi) and Peru Balsam (Myroxylon pereira) oils and blends of their constituents against mosquito, Aedes aegypti, acute toxicity on water flea, Daphnia magna and aqueous residue. J. Agric. Food Chem. 2012, 60, 5909-5914.

(62) Pavela, R.; Govindarajan, M. The essential oil from Zanthoxylum monophyllum a potential mosquito larvicide with low toxicity to the non-target fish Gambusia affinis. J. Pest. Sci. 2016, 90, 369-378.

(63) Pavela, R. Insecticidal properties of Pimpinella anisum essential oils against the Culex quinquefasciatus and the non-target organism Daphnia magna. J. Asia Pac. Entomol. 2014, 17, 287-293.

(64) Taoka, Y.; Nagano, N.; Okita, Y.; Izumida, H.; Sugimoto, S.; Hayashi, M. Effect of Tween 80 on the growth, lipid accumulation and fatty acid composition of Thraustochytrium aureum ATCC 34304. J. Biosci. Bioeng. 2011, 111, 420-424.

(65) da Silva Gündel, S.; Velho, M. C.; Diefenthaler, M. K.; Favarin, F. R.; Copetti, P. M.; de Oliveira Fogaça, A.; Klein, B.; Wagner, R.; Gündel, A.; Sagrillo, M. R.; Ourique, A. F. Basil oil-nanoemulsions: Development, cytotoxicity and evaluation of antioxidant and antimicrobial potential. J. Drug Deliv. Sci. Technol. 2018, 46, 378-383.

(66) Li, Y.; Wang, C.; Tao, Z.; Zhao, Z.; You, L.; Zheng, R.; Guo, X.; Zhang, Z. Enhanced antioxidant and antiproliferative activities of 
Cymbopogon citratus (DC.) Stapf essential oils in microemulsion. ACS

Sustain. Chem. Eng. 2019, 7, 15173-15181.

(67) Nuchuchua, O.; Sakulku, U.; Uawongyart, N.; Puttipipatkhachorn, S.; Soottitantawat, A.; Ruktanonchai, U. In vitro characterization and mosquito (Aedes aegypti) repellent activity of essential-oils-loaded nanoemulsions. AAPS PharmSciTech 2009, 10, 1234-1242.

(68) Jerobin, J.; Sureshkumar, R. S.; Anjali, C. H.; Mukherjee, A.; Chandrasekaran, N. Biodegradable polymer based encapsulation of neem oil nanoemulsion for controlled release of Aza-A. Carbohydr. Polym. 2012, 90, 1750-1756. 